\title{
Neuroprotective effect of panax notoginseng saponins and its main components
}

\author{
Xumei Wang, Shaoxia Wang", Limin $\mathrm{Hu}^{*}$ \\ Tianjin State Key Laboratory of Modern Chinese Medicine, Tianjin University of Traditional Chinese Medicine, Tianjin, China \\ Email: ${ }^{*}$ wangshaoxia1@163.com, ${ }^{*}$ huliminth@126.com
}

Received 1 October 2013; revised 2 November 2013; accepted 8 November 2013

Copyright (c) 2014 Xumei Wang et al. This is an open access article distributed under the Creative Commons Attribution License, which permits unrestricted use, distribution, and reproduction in any medium, provided the original work is properly cited. In accordance of the Creative Commons Attribution License all Copyrights (c) 2014 are reserved for SCIRP and the owner of the intellectual property Xumei Wang et al. All Copyright (C) 2014 are guarded by law and by SCIRP as a guardian.

\section{ABSTRACT}

Stroke is the third leading cause of death and the first cause of adult disability in industrial countries [1]. It is charicaterized by hemiplegia, hemianopsia, aphasia, mouth askew and sever sequelae. It is considered that an ischemic disease without any specific treatment method and few effective drugs such as tPA (human tissue-type plasminogen activator) and Edarovone with specific therapeutic window will cause a lot of disadvantages if being used inaccurate. Root of Panax notoginseng (PN) which is one of traditional Chinese medicines (TCMs), was first found in "Shennong's Classic of Materia Medica” around 200 AD. Panax notogineng saponins(PNS) is a multi-components mixture containing ginseng and saponins as the most important bioactive components which are commonly used in clinical treatment. Also, ginseng and saponins form the main components of many herbal medicines in the market, e.g., Xueshuantong injection [2], Xuesaitong injection [3], Xuesaitong soft capsule [4] and so on. The main monomers of Panax notoginseng saponins (PNS) are Ginsenoside-Rb1, Gensenoside-Rg1, Gensenoside-Re, Gensenoside-Rd and Panax notoginseng saponins-R1 [5]. In this review, we found some important points as well as shortcomings that require special consideration. We therefore highlighted the advances in neuro-protection of PNS and its main monomers in the area of experimental research.

\section{KEYWORDS}

Panax Notoginseng Saponins; Cerebral Ischemia; Neuro-Protection; Neuron Regeneration

\section{INTRODUCTION}

Stroke is an acute cerebrovascular disease, and is one of ${ }^{*}$ Corresponding authors. the most Chronic diseases affecting vulnerable human and it is the country's third-leading cause of death according to a Survey. More than 25\% of stroke survivors older than 65-year-old are disabled sooner before intervension. Stroke can be divided into two different syndromes according to different etiology: hemorrhagic stroke, cerebral hemorrhage, cerebral infarction and ischemic stroke. Clinically, PNS and its products are used regularly to treat stroke in China, and many experiments have been done to understand its mechanism. Through literature search using similar word or combination of words, we reviewed the recent advances in experimental research and use of PNS and its monomers as neuro-protective bioactive substance.

\section{PANAX NOTOGINSENG SAPONINS AND ITS MONOMERS}

\subsection{Panax Notoginseng Saponins (PNS)}

Experimentally, PNS can significantly improve symptoms after stroke and behavioral scores after animal nerve damages [6,7], improve animal's learning and Memor, reduce infarct size and edema [8] after cerebral ischemia. PN also has the ability to dilate Cerebral blood vessels, and increase cerebral blood flow. An experiment shows that PNS can make mean blood pressure (MBP) of femoral artery and cerebral vascular resistance decline in anesthetic rabbit and rat [9]. In addition, Determining the micro-vascular diameter and blood flow velocity of the meninges of anesthetized mice using JI-200 laser microcirculation dynamic analyzer, it was found that PNS can significantly speed up the velocity of blood flow, reduce brain ischemic hypoxia phenomena, and antagonism glutamate mediated excitatory poisoning [10]. This mechanism may be related to calcium channel blocking effect of PNS, reducing inflammation and slowing nerve apoptosis. PNS could block calcium in case of overload 
in nerve cells after brain injury [8,11], block $\mathrm{Ca}^{2+}$ and cell adhesion molecule (CaM) compounds forming, to reduce the release of free fatty acids and the generation of oxygen free radicals, reduce Malondialdehyde (MDA) content in blood and brain after brain ischemia, and may have protective effect on traumatic brain injury [12]. PNS can inhibit gene expression of caspase-3 and production and release of related inflammatory factors [13,14], and can affect the content of heat shock protein and the conversion protein [8]. PNS can significantly reduce neural cell apoptosis and the outflow of LDH [15], reduce NO content, TNF and IL-1 activity, to protect neuronal integrity after cerebral ischemia [16]. Thus PNS can alleviate inflammatory reaction of ischemia brain to protect the ischemia tissue.

\subsection{Ginsenoside-Rb1}

Ginsenoside-Rb1 is a main monomer of PNS. Rb1 can decrease the degree of cerebral edema, improve neurobehavioral score, protect vascular system from thickening and spasm [17], inhibit lipid peroxidation in the brain [18], improve the symptoms of stroke in early and late stage [19], and improve the learning ability after stroke [20]. Furthermore, Rb1 is able to expand average size of blood vessels, reduce the thickness of blood vessels in basilar part, Attenuate blood brain barrier (BBB) destruction, promote the expression of terminal deoxynucleotidyl transferase-mediated dUTP-biotin nick end labeling assay (TUNEL) after MCAO through resistant to apoptosis. After ischemia, Rb1 can weaken the activity of micro glia, decrease the up regulation of brain tissue mRNA tumor necrosis factor- $\alpha$ and interleukin-1 (IL-1), IL- $\beta$ and IL-6. Decreases expression of cox- 2 mRNA and protein content in brain tissue [21]. Rb1 can reduce infarct size, inflammation and nerve damage. Also, increase the expression of Glial-derived neurotrophic factor (GDNF), the number of BCL-2 positive cells, and inhibit apoptosis of nerve cells [22]. Thus, it is able to prolong response time after ischemia, prevent and delay neuronal cells apoptosis, and reduce vertebral nerve injury in Hippocampal CA1 area in the brain [23].

The inhibitory effect of Rb1 on local inflammation, may be related to cholinergic system and nerve nutrition system. After cerebral ischemia, Rb1 may increase the expression of choline acetyltransferase, kinase A mRNA of basal forebrain tyrosine and hippocampus nerve growth factor mRNA [24], increase hippocampus choline absorption to reduce the amount in cortex [25]. At the same time, Rb1 can promote stem cell proliferation and differentiation of hippocampus, increase its neural function and structural plasticity [26], increase the rate of hippocampus cell survival [27], protect neuron structure, and recover the amount of microtubule-associated protein LC3 and autophagy gene Beclin1.
The effect of neural protection and neuronal apoptosis inhibition after re-perfusion is linked to Increase expression of Bcl-2, and decrease expression of Bax [28]. Rb1 can selectively inhibit the activity of type- $1 \mathrm{Ca}^{2+}$ voltage-gated calcium channel of hippocampus [29], increase activity of $\mathrm{Na}^{+}$and $\mathrm{K}^{+}$ATPase and $\mathrm{Ca}^{2+}, \mathrm{Mg}^{2+}$ ATPase to reduce the flow of $\mathrm{Ca}^{2+}$ [30] on the synaptosome in rat cortical. Rb1 can increase the neurotransmitter release [31], can obviously decrease the height of phosphorylation level of the Tau protein [32].

\subsection{Ginsenoside-Rg1}

Ginsenoside Rg1 can inhibit lipid peroxidation in the brain [33], improve the learning ability and memory function of rats [34], improve the spatial learning ability, reduce the size of infarction area, promote Functional recovery of brain tissue [35]. By activating $\mathrm{Na}+$ and $\mathrm{K}+$ ATP enzyme within synaptic corpuscle of mouse [36], Rg1 can increase the concentration of cyclic adenosine monophosphate in the hippocampus [37]. Thus, it can have an effect on the central nervous system [38]. Rg1 can strengthen and stabilize the signaling pathways of HIF- $1 \alpha$, inhibit the activity of caspase-3 [39], facilitate the release of glutamate [40], to promote the recovery of brain, regulating cell survival, angiogenesis and neurogenesis [41,42]. Rg1 can accelerate the proliferation rate of neuronal cells [43] and neural stem cells [44,45] in cerebral cortex, and increased hippocampal dentate gyrus cell number $[46,47]$, protect the integrity of the nerve cells in the Structural arrangement [48], promote growth and differentiation of synapse [49], and change the hippocampus synaptic density without changing the synaptic plasticity. thus, improve spatial learning ability [50]. Rg1 can promote brain functional recovery [51], inhibit calcium accumulation, reduce potassium loss [52], reduce neuronal and cell apoptotic death by increasing the expression of Insulin-like growth factor One (IGF-1) in the brain [53]. Rg-1 can increase neuronal survival, reduce the release of $\mathrm{LDH}$, reduce the morphological changes of cells and the division of nuclear DNA.

\subsection{Ginsenoside-Rd}

Ginsenoside-Rd can attenuate the basal hypertrophic remodeling of the renal hypertensive rats, without affecting the overall blood pressure. While its mechanism may be related to Ginsenoside-Rd that can selectively compete with $\mathrm{Ca}^{2+}$ receptor [54], block $\mathrm{Ca}^{2+}$ influx, abate the expression of TRPM7 and ASIC1 $\alpha$ after ischemia $[55,56]$. After stroke, Rd can pass through the BBB to protect neurons [57], and inhibit the formation of hydroxyl, reduce production and accumulation of DNA, protein and lipid in the early stage, reduce oxidative and inflammatory damage $[58,59]$, decrease lactate accumu- 
lation from anaerobic glycolysis, increase the amount of pyruvate-production of aerobic glycolysis. Rd can protect nerve cells, relieve nerve injury, reduce inflammatory response within cortex and striatum [59], by protecting mitochondria, restoring energy, and reducing cell apoptosis $[59,60]$. Furthermore, it can reduce accumulation of ADP nucleotide caused by stroke, inhibit activity of PARP-1, attenuate nerve cell apoptosis and damage caused by inflammatory reaction [61].

Rd can increase L-Glutathione (GSH) content; improve antioxidant activity of catalase, superoxide dismutase (SOD), glutathione peroxidase to provide neural protection by reducing content of intracellular reactive oxygen species and the MDA [62]. Besides, Rd can promote the proliferation of neural stem cells without affecting the differentiation [63]. This provides us a reliable basis for the future treatment of nerve injury.

\subsection{Ginsenoside-Re}

Ginsenoside-Re can reduce lipid peroxide. It's mechanism is that $\mathrm{Re}$ can improve mitochondrial membrane fluidity by cutting a small viscosity, and increase activity of superoxide dismutase and GSH-Px [64]. The increase of MDA content in brain after reperfusion, prompt that oxidative stress reaction caused by brain injury is serious. While Re can reduce the MDA content, mitochondria swelling, and the apoptosis of $\mathrm{H}^{+}$-ATP in the brain [65].

\subsection{Panax Notoginseng Saponins-R1}

Notoginseng saponin R1 can protect viability of rat neural stem cells and neuronal cells from Glutamate (Glu) interference. Also it is found that R1 can inhibit over proliferation of cells and prevent intracellular free $\mathrm{Ca}^{2+}$ increases, reduce production of intracellular reactive oxygen species, inhibit potential depolarization process of mitochondrial membrane in the Glu, to block the pathway and inhibit the expression of Bcl-2 and up-regulate the expression of Bax. Reason for this is that the neural protective targets of R1 may be a complex receptor composed of N-methyl-D-aspartate (NMDA) and NR1/ NR2B [66].

\section{SUMMARY AND PROSPECT}

In clinical treatment, improving the cerebral blood supply can help reducing brain damage caused by chemia, and reducing the neuronal injury after cerebral ischemia/reperfusion, thereby promoting recovery of neural function. Panax notoginseng saponins have long been studied for its activities and its product. Xueshuantong injection has been used clinically, but the previous Studies have not met the international standard for drug discovery. Occlusion of the rat middle cerebral artery (MCAO) has approximately become the model of choice for mi- micking and studying the pathology and symptoms of human stroke $[67,68]$. But the mechanism and effect of ginseng on complex diseases are still unknown and need further study. With the rise in global demand for cerebrovascular drugs, the clinical application of notoginseng and its total saponins will have broader prospects in the field of medicine especially in the area of ischemic stroke.

\section{ACKNOWLEDGEMENTS}

This work was supported by the fund program named Major New Drugs Innovation and Development (2012ZX09101201-004).

\section{REFERENCES}

[1] Belayev, L., Khoutorova, L., Atkins, K.D. and Bazan, N.G. (2009) Robust docosahexaenoic acid-mediated neuroprotection in a rat model of transient, focal cerebral ischemia. Stroke, 40, 3121-3126. http://dx.doi.org/10.1161/STROKEAHA.109.555979

[2] Gao, L., Zhao, H., Liu, Q., Song, J., Xu, C., Liu, P., Gong, W., Wang, R., Liu, K.J. and Luo, Y. (2012) Improvement of hematoma absorption and neurological function in patients with acute intracerebral hemorrhage treated with Xueshuantong. Journal of the Neurological Sciences, 15, 236-240. http://dx.doi.org/10.1016/j.jns.2012.09.028

[3] Ai, W.B., Chen, Y.H. and Yang, Q.J. (2004) Clinical observation on effect of xuesaitong injection as auxiliary treatment of severe craniocerebral injury. Zhongguo Zhong Xi Yi Jie He Za Zhi, 24, 213-215.

[4] Zhong, S.Q., Sun, L.J., Yan, Y.Z., Sun, Y.Q. and Zhong, Y.Y. (2005) Effect of Xuesaitong soft capsule on hemorrheology and in auxiliarily treating patients with acute cerebral infarction. Chinese Journal of Integrative Medicine, 11, 128-131.

http://dx.doi.org/10.1007/BF02836469

[5] Li, S.P., Qiao, C.F., Chen, Y.W., Zhao, J., Cui, X.M., Zhang, Q.W., Liu, X.M. and Hu, D.J. (2013) A novel strategy with standardized reference extract qualification and single compound quantitative evaluation for quality control of Panax notoginseng used as a functional food. Journal of Chromatography A, 1313, 303-307. http://dx.doi.org/10.1016/j.chroma.2013.07.025

[6] Nie, Y.X., Wang, D. and Zhang, X. (2006) Effect of panax notoginseng saponins injection on brain edema in intracerebral hemorrhage rats. Zhongguo Zhong Xi Yi Jie He Za Zhi, 26, 922-925.

[7] Chen, X., Zhou, M., Li, Q., Yang, J., Zhang, Y., Zhang, D., Kong, S., Zhou, D. and He, L. (2008) Sanchi for acute ischaemic stroke. Cochrane Database of Systematic Reviews, 4. http://dx.doi.org/10.1002/14651858.CD006305.pub2

[8] Yao, X.H. and Li, X.J. (2002) Protective effects and its mechanism of panaxatriol saponins isolated from Panax notoginseng on cerebralischemia. Zhongguo Zhong Yao Za Zhi, 27, 371-373. 
[9] Wu, J.X. and Sun, J.J. (1992) Comparative effects of Panax notoginseng saponins, verapamil, and norepinephrine on cerebral circulation inanesthetized rats and rabbits. Zhongguo Yao Li Xue Bao, 13, 520-523.

[10] Ma, L., Xiao, P., Guo, B., Wu, J., Liang, F. and Dong, S. (1999) Cerebral protective effects of some compounds isolated from traditional Chinese herbs. Zhongguo Zhong Yao Za Zhi, 24, 238-239, 256-inside back cover.

[11] Ma, L.Y., Xiao, P.G., Liang, F.Q., Chi, M.G. and Dong, S.J. (1997) Effect of saponins of Panax notoginseng on synaptosomal 45Ca uptake. Zhongguo Yao Li Xue Bao, 18, 213-215.

[12] Han, J., Hu, W. and Sun, Z. (1999) Effect of Panax notoginseng saponin on $\mathrm{Ca}^{2+}$, CaM in craniocerebral injury. Zhongguo Zhong Xi Yi Jie He Za Zhi, 19, 227-229.

[13] Tang, Y.H., Zhang, S.P., Liang, Y. and Deng, C.Q. (2007) Effects of Panax notoginseng saponins on mRNA expressions of interleukin-1 beta, its correlative factors andcysteinyl-aspartate specific protease after cerebral ischemia-reperfusion in rats. Zhong Xi Yi Jie He Xue Bao, 5, 328-332. http://dx.doi.org/10.3736/jcim20070319

[14] Li, H., Deng, C.Q., Chen, B.Y., Zhang, S.P., Liang, Y. and Luo, X.G. (2009) Total saponins of Panax notoginseng modulate the expression of caspases and attenuate apoptosis in ratsfollowing focal cerebral ischemia-reperfusion. Journal of Ethnopharmacology, 30, 412-418. http://dx.doi.org/10.1016/j.jep.2008.10.042

[15] Zhu, L.Q., Fan, J.P., Huang, Q.F., Sun, S.L., Gao, Y., Zou, Y.H., Zhang, Z., He, L.Y.and Zheng, H. (2003) Study on the anti-apopotosis induced by hypoxia/hypoglycemia and reoxygenation of panax notoginseng saponins in cultured rat hippocampal neurons. Zhongguo Zhong Yao Za Zhi, 28, 52-55.

[16] Jiang, K.Y. and Qian, Z.N. (1995) Effects of Panax notoginseng saponins on posthypoxic cell damage of neurons in vitro. Zhongguo Yao Li Xue Bao, 16, 399-402.

[17] Lee, S.H., Jung, B.H., Kim, S.Y., Lee, E.H. and Chung, B.C. (2006) The antistress effect of ginseng total saponin and ginsenoside Rg3 and Rb1 evaluated by brain polyamine levelunder immobilization stress. Pharmacological Research, 54, 46-49. http://dx.doi.org/10.1016/j.phrs.2006.02.001

[18] Deng, H.L. and Zhang, J.T. (1991) Anti-lipid peroxilative effect of ginsenoside Rb1 and Rg1. Chinese Medical Journal (English Edition), 104, 395-398.

[19] Yoshikawa, T., Akiyoshi, Y., Susumu, T., Tokado, H., Fukuzaki, K., Nagata, R., Samukawa, K., Iwao, H. and Kito, G. (2008) Ginsenoside Rb1 reduces neurodegeneration in the peri-infarct area of a thromboembolic stroke model in non-human primates. Journal of Pharmacological Sciences, 107, 32-40. http://dx.doi.org/10.1254/jphs.FP0071297

[20] Mook-Jung, I., Hong, H.S., Boo, J.H., Lee, K.H., Yun, S.H., Cheong, M.Y., Joo, I., Huh, K. and Jung, M.W. (2001) Ginsenoside Rb1 and Rg1 improve spatial learning and increase hippocampal synaptophysin level in mice. Journal of Neuroscience Research, 63, 509-515. http://dx.doi.org/10.1002/jnr.1045
[21] Lee, J.S., Song, J.H., Sohn, N.W. and Shin, J.W. (2012) Inhibitory Effects of Ginsenoside Rb1 on Neuroinflammation Following Systemic Lipopolysaccharide Treatment inMice. Phytotherapy Research, 27, 1270-1276. http://dx.doi.org/10.1002/ptr.4852

[22] Yuan, Q.L., Yang, C.X., Xu, P., Gao, X.Q., Deng, L., Chen, P., Sun, Z.L. and Chen, Q.Y. (2007) Neuroprotective effects of ginsenoside Rb1 on transient cerebral ischemia in rats. Brain Research, 1167, 1-12. http://dx.doi.org/10.1016/j.brainres.2007.06.024

[23] Wen, T.C., Yoshimura, H., Matsuda, S., Lim, J.H. and Sakanaka, M. (1996) Ginseng root prevents learning disability and neuronal loss in gerbils with 5-minute forebrain ischemia. Acta Neuropathologica, 91, 15-22. http://dx.doi.org/10.1007/s004010050387

[24] Salim, K.N., McEwen, B.S. and Chao, H.M. (1997) Ginsenoside Rb1 regulates ChAT, NGF and trkA mRNA expression in the rat brain. Molecular Brain Research, 47, 177-182. http://dx.doi.org/10.1016/S0169-328X(97)00042-9

[25] Benishin, C.G. (1992) Actions of ginsenoside Rb1 on choline uptake in central cholinergic nerve endings. $\mathrm{Neu}$ rochemistry International, 21, 1-5. http://dx.doi.org/10.1016/0197-0186(92)90061-U

[26] Cheng, Y., Shen, L.H. and Zhang. J.T. (2005) Anti-amnestic and anti-aging effects of ginsenoside Rg1 and Rb1 and its mechanism of action. Acta Pharmacologica Sinica, 26, 143-149. http://dx.doi.org/10.1111/j.1745-7254.2005.00034.X

[27] Liu, L., Hoang-Gia, T., Wu, H., Lee, M.R., Gu, L., Wang, C., Yun, B.S., Wang, Q., Ye, S. and Sung, C.K. (2011) Ginsenoside Rb1 improves spatial learning and memory by regulation of cell genesis in the hippocampalsubregions of rats. Brain Research, 1382, 147-154. http://dx.doi.org/10.1016/j.brainres.2011.01.051

[28] Yang, C.X., Liu, J.X., Sun, Z.L., Gao, X.Q., Deng, L. and Yuan, Q.L. (2008) Effects of Ginsenoside RB1 on neural cell apoptosis and expressions of $\mathrm{Bcl}-2$ and $\mathrm{Bax}$ in rats followingsubjected to cerebral ischemia-reperfusion. Sichuan Da Xue Xue Bao Yi Xue Ban, 39, 214-217.

[29] Lin, Z.Y., Chen, L.M., Zhang, J., Pan, X.D., Zhu, Y.G., Ye, Q.Y., Huang, H.P. and Chen, X.C. (2012) Ginsenoside Rb1 selectively inhibits the activity of L-type voltage-gated calcium channels in cultured rathippocampal neurons. Acta Pharmacologica Sinica, 33, 438-44. http://dx.doi.org/10.1038/aps.2011.181

[30] Jiang, X.Y., Zhang, J.T. and Shi, C.Z. (1996) Mechanism of action of ginsenoside Rb1 in decreasing intracellular $\mathrm{Ca}^{2+}$. Yaо Хие Хие Вao, 31, 321-326.

[31] Xue, J.F., Liu, Z.J., Hu, J.F., Chen, H., Zhang, J.T. and Chen, N.H. (2006) Ginsenoside Rb1 promotes neurotransmitter release by modulating phosphorylation of synapsins through acAMP-dependent protein kinase pathway. Brain Research, 1106, 91-98. http://dx.doi.org/10.1016/j.brainres.2006.05.106

[32] Song, J.Q., Chen, X.C., Zhang, J., Huang, T.W., Zeng, Y.Q., Shen, J. and Chen, L.M. (2008) JNK/p38 MAPK involves in ginsenoside Rb1 attenuating beta-amyloid peptide (25-35) -induced tau proteinhyperphosphorylation in embryo rat cortical neurons. Yao Хие Хие Bao, 43, 
29-34.

[33] Deng, H.L. and Zhang, J.T. (1991) Anti-lipid peroxilative effect of ginsenoside Rb1 and Rg1. Chinese Medical Journal (English Edition), 104, 395-398.

[34] Li, Y., Tu, L., Chen, D., Jiang, R., Wang, Y. and Wang, S. (2012) Study on functional recovery of hypoxic-ischemic brain injury by Rg1-induced NSCs. Zhongguo Zhong Yao Za Zhi, 37, 509-514.

[35] Li, W.K., Ran, W.B., Su, Y.W. and Huang, F.J. (2008) Effects of ginsenoside Rg1 on expression of insulin-like growth factor-1 in brain of rats with brain contusion. Zhong Xi Yi Jie He Xue Bao, 6, 911-914. http://dx.doi.org/10.3736/jcim20080907

[36] Jin, L.Q. and Shi, L. (1991) Effects of saponins of Panax notoginseng on sodium-potassium-adenosine triphosphatase and calcium-magnesium-adenosine triphosphatase. Zhongguo Yao Li Xue Bao, 12, 504-506.

[37] Liu, M. and Zhang, J.T. (1996) Effects of ginsenoside Rg1 on c-fos gene expression and cAMP levels in rat hippocampus. Zhongguo Yao Li Xue Bao, 17, 171-174.

[38] Stancheva, S.L. and Alova, L.G. (1993) Ginsenoside Rg1 inhibits the brain CAMP phosphodiesterase activity in young and aged rats. General Pharmacology, 24, 14591462. http://dx.doi.org/10.1016/0306-3623(93)90435-Z

[39] Wang, D., Huang, Y., Li, Q., Xu, S. and Liu, X. (2010) Anti-apoptotic effect of ginsenoside Rg1 on neuron after neonatal hypoxia ischemia brain damage. Zhongguo Xiu Fu Chong Jian Wai Ke Za Zhi, 24, 1107-1112.

[40] Liu, Z.J., Zhao, M., Zhang, Y., Xue, J.F. and Chen, N.H. (2010) Ginsenoside Rg1 promotes glutamate release via a calcium/calmodulin-dependent protein kinase II-dependent signaling pathway. Brain Research, 1333, 1-8. http://dx.doi.org/10.1016/j.brainres.2010.03.096

[41] Tang, B., Qu, Y., Wang, D. and Mu, D. (2011) Targeting hypoxia inducible factor- $1 \alpha$ : A novel mechanism of ginsenoside Rg1 for brain repair afterhypoxia/ischemia brain damage. CNS \& Neurological Disorders-Drug Targets, 10, 235-238. http://dx.doi.org/10.2174/187152711794480456

[42] Wang, D.J., Li, Q.Y., Xu, S.J. and Zeng, N. (2011) Effect of ginsenoside Rg1 on angiogenesis after neonatal hypoxia ischemia brain damage in rats. Sichuan Da Xue Xue Bao Yi Xue Ban, 42, 503-507.

[43] Himi, T., Saito, H. and Nishiyama, N. (1989) Effect of ginseng saponins on the survival of cerebral cortex neurons in cell cultures. Chemical \& Pharmaceutical Bulletin (Tokyo), 37, 481-484.

http://dx.doi.org/10.1248/cpb.37.481

[44] Shen, L.H. and Zhang, J.T. (2003) Culture of neural stem cells from cerebral cortex of rat embryo and effects of drugs on the proliferation ability ofstem cells. Yao Xue Хие Ваo, 38, 735-738.

[45] Lu, Z.F., Shen, Y.X., Zhang, P., Xu, Y.J., Fan, Z.H., Cheng, M.H. and Dong, Q.R. (2010) Ginsenoside Rg1 promotes proliferation and neurotrophin expression of olfactory ensheathing cells. Journal of Asian Natural Products Research, 12, 265-272. http://dx.doi.org/10.1080/10286021003689791
[46] Shen, L. and Zhang, J. (2003) Ginsenoside Rg1 increases ischemia-induced cell proliferation and survival in the dentate gyrus of adult gerbils. Neuroscience Letters, 344, 1-4. http://dx.doi.org/10.1016/S0304-3940(03)00318-5

[47] Shen, L.H. and Zhang, J.T. (2004) Ginsenoside Rg1 promotes proliferation of hippocampal progenitor cells. Neurological Research, 26, 422-428. http://dx.doi.org/10.1179/016164104225016047

[48] Chen, Z.Y., Du, T.M. and Chen, S.C. (2011) Effects of ginsenoside Rg1 on learning and memory function and morphology of hippocampal neurons of ratswith electrical hippocampal injuries. Nan Fang Yi Ke Da Xue Xue Bao, 31, 1039-1042.

[49] Wang, L. and Kisaalita, W.S. (2011) Administration of BDNF/ginsenosides combination enhanced synaptic development in human neural stem cells. Journal of Neuroscience Methods, 194, 274-282.

http://dx.doi.org/10.1016/j.jneumeth.2010.10.025

[50] Mook-Jung, I., Hong, H.S., Boo, J.H., Lee, K.H., Yun, S.H., Cheong, M.Y., Joo, I., Huh, K. and Jung, M.W. (2001) Ginsenoside Rb1 and Rg1 improve spatial learning and increase hippocampal synaptophysin level in mice. Journal of Neuroscience Methods, 63, 509-515. http://dx.doi.org/10.1002/jnr.1045

[51] Li, W.K., Ran, W.B., Su, Y.W. and Huang, F.J. (2008) Effects of ginsenoside Rg1 on expression of insulin-like growth factor-1 in brain of rats with brain contusion. Zhong Xi Yi Jie He Xue Bao, 6, 911-914. http://dx.doi.org/10.3736/jcim20080907

[52] Zhang, Y.G. and Liu, T.P. (1996) Influences of ginsenosides Rb1 and Rg1 on reversible focal brain ischemia in rats. Zhongguo Yao Li Xue Bao, 17, 44-48.

[53] Zhang, Y.F., Fan, X.J., Li, X., Peng, L.L., Wang, G.H., Ke, K.F. and Jiang, Z.L. (2008) Ginsenoside Rg1 protects neurons from hypoxic-ischemic injury possibly by inhibiting $\mathrm{Ca}^{2+}$ influx through NMDAreceptors and L-type voltage-dependent $\mathrm{Ca}^{2+}$ channels. European Journal of Pharmacology, 586, 90-99. http://dx.doi.org/10.1016/j.ejphar.2007.12.037

[54] Liu, X., Xia, J., Wang, L., Song, Y., Yang, J., Yan, Y., Ren, H. and Zhao, G. (2009) Efficacy and safety of ginsenoside-Rd for acute ischaemic stroke: A randomized, doubleblind, placebo-controlled, phase II multicenter trial. European Journal of Neurology, 16, 569-575. http://dx.doi.org/10.1111/j.1468-1331.2009.02534.x

[55] Zhang, Y., Zhou, L., Zhang, X., Bai, J., Shi, M. and Zhao, G. (2012) Ginsenoside-Rd attenuates TRPM7 and ASIC1a but promotes ASIC2a expression in rats after focal cerebralischemia. Neurological Sciences, 33, 1125-1131. http://dx.doi.org/10.1007/s10072-011-0916-6

[56] Cai, B.X., Li, X.Y., Chen, J.H., Tang, Y.B., Wang, G.L., Zhou, J.G., Qui, Q.Y. and Guan, Y.Y. (2009) Ginsenoside$\mathrm{Rd}$, a new voltage-independent $\mathrm{Ca}^{2+}$ entry blocker, reverses basilar hypertrophic remodeling instroke-prone renovascular hypertensive rats. European Journal of Pharmacology, 606, 142-149. http://dx.doi.org/10.1016/j.ejphar.2009.01.033

[57] Ye, R., Kong, X., Yang, Q., Zhang, Y., Han, J., Li, P., Xiong, L. and Zhao, G. (2011) Ginsenoside Rd in experi- 
mental stroke: Superior neuroprotective efficacy with a wide therapeutic window. Neurotherapeutics, 8, 515-525. http://dx.doi.org/10.1007/s13311-011-0051-3

[58] Ye, R., Yang, Q., Kong, X., Han, J., Zhang, X., Zhang, Y., Li, P., Liu, J., Shi, M., Xiong, L. and Zhao, G. (2011) Ginsenoside Rd attenuates early oxidative damage and sequential inflammatory response after transient focalischemia in rats. Neurochemistry International, 58, 391398. http://dx.doi.org/10.1016/j.neuint.2010.12.015

[59] Ye, R., Kong, X., Yang, Q., Zhang, Y., Han, J. and Zhao, G. (2011) Ginsenoside Rd attenuates redox imbalance and improves stroke outcome after focal cerebral ischemia in aged mice. Neuropharmacology, 61, 815-824. http://dx.doi.org/10.1016/j.neuropharm.2011.05.029

[60] Ye, R., Zhang, X., Kong, X., Han, J., Yang, Q., Zhang, Y., Chen, Y., Li, P., Liu, J., Shi, M., Xiong, L. and Zhao, G. (2011) Ginsenoside Rd attenuates mitochondrial dysfunction and sequential apoptosis after transient focal ischemia. Neuroscience, 178, 169-180. http://dx.doi.org/10.1016/j.neuroscience.2011.01.007

[61] Hu, G., Wu, Z., Yang, F., Zhao, H., Liu, X., Deng, Y., Shi, M. and Zhao, G. (2013) Ginsenoside Rd blocks AIF mitochondrio-nuclear translocation and NF- $\mathrm{KB}$ nuclear accumulation by inhibitingpoly(ADP-ribose) polymerase-1 after focal cerebral ischemia in rats. Neurological Sciences, 34, 2101-2106. http://dx.doi.org/10.1007/s10072-013-1344-6

[62] Ye, R., Li, N., Han, J., Kong, X., Cao, R., Rao, Z. and Zhao, G. (2009) Neuroprotective effects of ginsenoside $\mathrm{Rd}$ against oxygen-glucose deprivation in cultured hippocampal neurons. Neuroscience Research, 64, 306-310. http://dx.doi.org/10.1016/j.neures.2009.03.016

[63] Lin, T., Liu, Y., Shi, M., Liu, X., Li, L., Liu, Y. and Zhao,
G. (2012) Promotive effect of ginsenoside Rd on proliferation of neural stem cells in vivo and in vitro. Journal of Ethnopharmacology, 142, 754-761. http://dx.doi.org/10.1016/j.jep.2012.05.057

[64] Zhou, X.M., Cao, Y.L. and Dou, D.Q. (2006) Protective effect of ginsenoside-Re against cerebral ischemia/reperfusion damage in rats. Biological and Pharmaceutical Bulletin, 29, 2502-2505. http://dx.doi.org/10.1248/bpb.29.2502

[65] Chen, L.M., Zhou, X.M., Cao, Y.L. and Hu, W.X. (2008) Neuroprotection of ginsenoside $\mathrm{Re}$ in cerebral ischemiareperfusion injury in rats. Journal of Asian Natural Products Research, 10, 439-445. http://dx.doi.org/10.1080/10286020801892292

[66] Gu, B., Nakamichi, N., Zhang, W.S., Nakamura, Y., Kambe, Y., Fukumori, R., Takuma, K., Yamada, K., Takarada, T., Taniura, H. and Yoneda, Y. (2009) Possible protection by notoginsenoside R1 against glutamate neurotoxicity mediated by N-methyl-D-aspartatereceptors composed of an NR1/NR2B subunit assembly. Journal of Neuroscience Research, 87, 2145-2156. http://dx.doi.org/10.1002/jnr.22021

[67] Hunter, A.J., Mackay, K.B. and Rogers, D.C. (1998) To what extent have functional studies of ischaemia in animals been useful in the assessment of potential neuroprotective agents? Trends in Pharmacological Sciences, 19, 59-66. http://dx.doi.org/10.1016/S0165-6147(97)01157-7

[68] Hossmann, K.A. (1991) Animal models of cerebral ischemia, 1: Review of literature. Cerebrovascular Diseases, 1, 2-15. 